Tourism in Analysis

DOI: http://dx.doi.org/10.11606/issn.1984-4867.v27i3p568-595

\title{
Os Produtos Turísticos de Curitiba, PR, Brasil na Perspectiva de Gestores de Agências de Turismo Receptivo
}

\author{
The tourism products of Curitiba, PR, Brazil, from the perspective of \\ managers of incoming travel agencies
}
Los productos turísticos de Curitiba, PR, Brasil, según la perspectiva de gestores de agencias de turismo receptivo

\author{
Raquel Pazini ${ }^{1}$ \\ José Manoel Gonçalves Gândara²
}

\begin{abstract}
Resumo
As agências de turismo são responsáveis pela comercialização de produtos e serviços turísticos. No mercado receptivo, as agências são especializadas em oferecer serviços e produtos para o turista conhecer o destino, com diversas opções de roteiros para atrativos locais e regionais. $\mathrm{O}$ apoio e a assistência do guia de turismo durante os passeios são aspectos fundamentais para atender às motivações dos turistas. A inovação e a criatividade, bem como a experiência e a perspectiva emocional, são elementos essenciais na conformação de produtos turísticos que busquem a satisfação do cliente e a competitividade no mercado. $\mathrm{O}$ objetivo deste estudo foi analisar os produtos comercializados pelas agências de turismo receptivo localizadas em Curitiba, PR, Brasil, a partir de dados relacionados a criatividade, inovação, experiência e emoção, na percepção dos gestores das agências. Foram empregadas metodologia qualitativa, com revisão bibliográfica e documental relacionada à temática proposta, e uso de conceitos teóricos para definição dos indicadores utilizados nas entrevistas semiestruturadas, realizadas em profundidade com os gestores das principais agências de turismo receptivo atuantes na cidade. Os resultados demonstraram que os passeios mais vendidos não são os mais criativos e inovadores, e também não permitem vivenciar as diferentes dimensões das experiências e emoções. No entanto, a maioria das agências relaciona o produto mais comercializado com uma experiência de qualidade, buscando a satisfação do turista e a qualidade da visitação.
\end{abstract}

Palavras-chave: Agências de turismo receptivo; Produto turístico; Criatividade e inovação; Experiência e emoção; Curitiba, PR, Brasil.

\footnotetext{
1 Mestre em Turismo pela Universidade Federal do Paraná (UFPR). Especialização em Gestão Estratégica de Empresas Turísticas e Gestão da Aprendizagem pela Universidade Positivo. Curitiba, Paraná, Brasil. E-mail: raquelpazini@hotmail.com

2 Doutor em Turismo e Desenvolvimento Sustentável pela Universidad de Las Palmas de Gran Canária, Espanha (ULPGC). Mestre em Gestão do Turismo pela Scuola Superiore del Commercio del Turismo i dei Servizzi de Milão, Itália. Docente e Pesquisador do Departamento de Turismo, do curso de Graduação em Turismo, do Mestrado e Doutorado em Geografia e do Mestrado em Turismo da Universidade Federal do Paraná (UFPR). Curitiba, Paraná, Brasil. E-mail: jmggandara@yahoo.com.br
} 
Tourism in Analysis

\begin{abstract}
Travel agencies are responsible for selling tourism products and services. At the incoming market, these travel agencies are specialized in offering services and products to tourists, with many itineraries involving local and regional tourist attractions. Tour guide support and assistance during tours are fundamental to know the motivations of tourists. Innovation and creativity, as well as experience and emotional perspective are crucial elements in creating tourism products intended to customer's satisfaction and market competitiveness. The aim of this study was to analyze the products commercialized by incoming travel agencies located at Curitiba, from elements related to creativity, innovation, experience and emotion, according the perception of travel agencies managers. A qualitative methodology was used, with a literature review on the subject, and proposed use of theoretical concepts for defining the indicators used in the semi structured deep-interviews, with managers of the main incoming travel agencies located in Curitiba, PR, Brazil. The results showed that the most commercialized tours are not the most creative and innovative, and also do not allow the dimensions of experience and emotions. However, many of the incoming travel agencies related the most commercialized tours with a quality experience, focused on tourist satisfaction and quality of visit.
\end{abstract}

Keywords: Incoming travel agencies; Tourism products; Creativity and innovation; Experience and emotion; Curitiba, PR, Brazil.

\title{
Resumen
}

Las agencias de turismo son responsables de la comercialización de productos y servicios turísticos. En el mercado receptivo, las agencias son especializadas en ofrecer servicios y productos para que los turistas conozcan el destino, con diversas opciones de circuitos para presentarles los atractivos locales y regionales. El apoyo y la asistencia del guía de turistas durante la realización de los paseos son aspectos fundamentales para atender las motivaciones y el perfil de los turistas. La innovación y la creatividad, así como la experiencia y la perspectiva emocional, son elementos esenciales en la conformación de productos turísticos en aras de la satisfacción del cliente y teniendo presente la competitividad del mercado. El objetivo de este estudio fue analizar los productos comercializados por las agencias de turismo receptivo ubicadas en la ciudad Curitiba, PR, Brasil, a partir del análisis de los elementos creatividad, innovación, experiencia y emoción, desde la percepción de los gestores de las agencias. Ha sido empleada la metodología cualitativa, con revisión bibliográfica y documental relacionada a la temática propuesta, así como la utilización de conceptos teóricos para la definición de los indicadores utilizados en las entrevistas semiestructuradas realizadas con los gestores de las principales agencias de turismo receptivo que actúan en esta ciudad. Los resultados han demostrado que los paseos más vendidos no son los más creativos e innovadores, además de que no permiten vivenciar las diferentes dimensiones de las experiencias y emociones. Pero la mayoría de las agencias relaciona el producto más comercializado con una experiencia de calidad, enfocada en la satisfacción del turista y en la calidad de la visita. Palabras clave: Agencias de turismo receptivo; Producto turístico; Creatividad e innovación; Experiencia y emoción; Curitiba, PR, Brasil. 


\section{Introdução}

O turismo receptivo está relacionado a uma infraestrutura organizacional e logística voltada para elaboração e comercialização de produtos, com o propósito de apresentar os atrativos turísticos de uma cidade ou região, compondo um conjunto de serviços planejados para atender o turista no núcleo receptor (PELIZZER, 2007; MATOS, 2012). As possibilidades de produtos e serviços específicos para uma operadora de turismo receptivo são: traslados; city tours, passeios ou circuitos temáticos; excursões e outros serviços, como guias de turismo, receptivo em eventos e intermediação para espetáculos e eventos esportivos (ASTORINO, 2008). No cenário atual do mercado, normalmente os produtos e serviços são tradicionais e similares, por isso a agência deve buscar uma vantagem competitiva, que pode ser em facilidades durante o passeio (ingressos de atrações, degustação, brindes e surpresas), descontos exclusivos em estabelecimentos parceiros (lojas de artesanato local e restaurantes), além de atendimento e serviço eficiente e de qualidade, que sejam valorizados pelo turista (ABAV; SEBRAE, 2010). A cidade de Curitiba, capital do estado do Paraná, tem uma imagem de cidade-modelo, que faz parte das estratégias de planejamento urbano e constitui uma atração para o turismo, seja pela estrutura física, seja pelo caráter simbólico (OLIVEIRA; RECHIA, 2009). As agências de turismo receptivo se valem dessa atratividade para elaboração de produtos que levem o turista a vivenciar uma melhor experiência na cidade, com o acompanhamento de guias de turismo que abordam as características de cada lugar visitado.

Em função da relevância do turismo receptivo como atividade organizada e de desenvolvimento para o destino, o objetivo deste estudo foi analisar os produtos comercializados pelas agências de turismo receptivo localizadas em Curitiba (PR), a partir da análise dos elementos de criatividade, inovação, experiência e emoção, na percepção dos empresários do setor. A metodologia da pesquisa teve um caráter qualitativo que, além da pesquisa bibliográfica, utilizou entrevistas semiestruturadas com agências de turismo receptivo de Curitiba. As questões foram elaboradas a partir dos modelos Creative Product Analysis Matrix (CPAM) (BESEMER, 1998; BESEMER; TREFFINGER, 1981); economia da experiência e experiência do turista no destino (PINE II; GILMORE, 1999; PULIDO-FERNÁNDEZ; NAVARRO HERMOSO, 2014); e teoria do fluxo (ARNOULD; PRICE, 1993;CARL III, 1994;CSIKSZENTMIHALYI, 1975). Esses modelos teóricos foram selecionados por permitir adequar as análises dos resultados às dimensões de criatividade, inovação, experiência 
Tourism in Analysis

e emoção, aspectos inter-relacionados na construção de experiências turísticas de qualidade, passíveis de ser encontradas nos produtos de turismo receptivo em Curitiba.

As reflexões teóricas abordaram inicialmente o papel das agências no mercado de turismo receptivo, voltadas para elaboração e comercialização de produtos e serviços turísticos. Trataram também da relação com os conceitos de criatividade, inovação, experiência e emoção, que servem de base para as análises dos resultados da pesquisa.

\section{Agenciamento e turismo receptivo}

A estrutura do sistema produtivo do turismo receptivo inclui aspectos básicos, em que a oferta turística no destino abrange hospedagem, transportes, alimentação, lazer/recreação, atrações turísticas, recursos humanos (guias de turismo, motoristas, atendentes) e venda de produtos (artesanato, souvenirs). Além disso, engloba os aspectos de governança na gestão da atividade turística, envolvendo o Governo (órgãos oficiais de turismo), a iniciativa privada (empresários do setor), as entidades de classe, e a participação da comunidade local (PELIZZER, 2007).

Segundo Braga (2008), nesse mercado existe uma segmentação de agências especializadas em receber o turista, responsáveis pela elaboração e operacionalização de produtos no destino. Machado e Almeida (2010) comentam que essas agências de receptivo ainda são pouco estudadas no meio acadêmico, apesar de sua importância na conformação de produtos e desenvolvimento de destinos turísticos. De acordo com Astorino (2008), as possibilidades de produtos e serviços específicos de uma agência de turismo receptivo incluem:

- Transportes: traslados de/para aeroporto, hotéis, restaurantes etc.

- Roteiros: passeios ou circuitos temáticos; excursões; city tours:

- City tour: inclui os atrativos mais relevantes e de maior destaque turístico de uma cidade, podendo ter duração de meio dia ou dia inteiro, conforme o roteiro e tempo de visitação em cada local;

- City tour by night: realizado nos atrativos que possuem um diferencial ou uma iluminação especial à noite, e costuma oferecer paradas em restaurantes ou bares, conforme o perfil de cada local;

- City tour personalizado: atende o interesse específico de um grupo.

- Outros serviços: guias de turismo; receptivo em eventos; intermediação para espetáculos e eventos esportivos. 
De acordo com Bahl e Nitsche (2012), os roteiros relacionam-se diretamente com a estrutura do turismo emissivo e receptivo, tendo a agência de turismo como o ponto central da operação, agregando serviços e elaborando produtos à disposição dos turistas. Eles permitem a comercialização do destino como produto turístico e, por isso, se constituem em uma das principais formas de desenvolver os atrativos de um local ou região. Os roteiros permitem também a articulação dos atrativos, o que facilita a visita do turista a um local inicialmente desconhecido (TAVARES, 2002). Durante a execução dos passeios destacam-se as habilidades do guia de turismo, pois sua personalidade e perspectiva pessoal sobre as atrações visitadas influenciam a experiência e o envolvimento emocional do turista (HOLLOWAY, 1981). Canani (1999, p. 92) considera a "importância do exercício da profissão de guia de turismo no Brasil como elemento propiciador de qualidade nos serviços turísticos desenvolvidos por agências de turismo e outras empresas do setor".

Nesse contexto, a agência precisa adotar uma política de turismo responsável, ética e sustentável, que oriente as práticas no destino, com respeito à população local, estímulo à conscientização ambiental, valorização da autenticidade da cultura, e atuação profissional responsável do guia, que deve estar comprometido com a satisfação e a experiência do turista, e não apenas com interesses comerciais (ASTORINO, 2008).

\section{Dimensões da criatividade e inovação}

Com a alta competitividade entre os produtos e a incerteza do ambiente de mercado, relacionada ao curto ciclo de vida de produtos e serviços, o desenvolvimento deles não deve apenas enfocar a satisfação das necessidades e dos desejos dos clientes, mas incluir valores criativos e inovadores (HSIAO; CHOU, 2004). O propósito da inovação envolve uma busca das organizações por mudanças (AMABILE, 1988) e a adaptação de alguns produtos (HJALAGER, 2002). Assim, um processo satisfatório de inovação corporativa no turismo garante rentabilidade - mesmo em um mercado competitivo - e agrega valor ao produto e à experiência do turista (WEIERMAIR, 2004).

Para Besemer e Treffinger (1981), os produtos são considerados o resultado tangível do processo criativo. Dessa forma, tanto a originalidade como a utilidade e o valor são propriedades 
do produto criativo. As pessoas envolvidas no planejamento e no desenvolvimento de serviços e produtos precisam encontrar caminhos que avaliem a criatividade neles contida, pois ao colocá-los no mercado é preciso que estejam adequados ao que está sendo procurado pelo consumidor, em termos não só de criatividade, mas também de qualidade (CROPLEY; KAUFMAN; CROPLEY, 2011).

De acordo com Horn e Salvendy (2006), o produto criativo não é simplesmente o que foi originado no processo de criatividade ou o ponto de partida da empresa para a inovação. Partindo do pressuposto de que toda inovação começa com ideias criativas, Amabileet al. (1996) definem a criatividade pela produção de ideias novas e úteis, desenvolvidas por uma pessoa ou grupo, com diversas habilidades e percepções, no contexto de uma organização, enquanto a inovação pode ser entendida pela implementação satisfatória de ideias criativas. Haner (2005) enfatiza a justaposição entre os conceitos de inovação e criatividade destacando que eles contêm características e padrões comuns que permitem uma reflexão conjunta, porque o primeiro passo dentro do processo de inovação é gerar ideias criativas. Nesse contexto, Cropley, Kaufman e Cropley (2011) definem que a criatividade é a síntese de novas ideias e conceitos por meio da reestruturação radical das já existentes, enquanto a inovação é a aplicação dos resultados oriundos da criatividade.

Dessa forma, Soares et al. (2013) ressaltam a importância de as empresas terem um direcionamento para a inovação, buscando criar e recriar produtos que atendam a tendências e novos conceitos de mercado, para, acima de tudo, satisfazer as necessidades dos consumidores que desejam um produto ao qual possam acrescentar significado pessoal, e que lhes possibilite a geração de experiências autênticas.

\section{Dimensões da experiência e da emoção}

Enquanto bens são tangíveis e serviços são intangíveis, as experiências são memoráveis, além de únicas e diferenciadas para cada indivíduo, e, por conseguinte, não passíveis de padronização. Isso implica mudanças na prática de vender e consumir viagens, para que se vivencie mais e melhor cada destino (PINE II; GILMORE, 1999). Dessa maneira, o destino é considerado o palco das experiências turísticas (CARBALLO FUENTES et al., 2015). 
Nesse sentido, Pine II e Gilmore (1999) e Jensen (1999), salientam que os turistas buscam serviços/destinos que retratem uma história, para que a experiência se torne mais do que viajar, transformando-se em vivência emocionante, que será narrada a outros. Desse modo, o turismo ganha destaque dentro dessa perspectiva, ao oferecer como produto principal a vivência de experiências aos consumidores (GIMENES; BIZINELLI; MANOSSO, 2012).O pensamento dentro da "nova sociedade", a qual Jensen (1999) denomina Sociedade dos Sonhos, deve ser o de buscar elementos que satisfaçam as demandas emocionais, ou seja, deve-se buscar maximizar tanto as emoções quanto as experiências dos turistas, por intermédio da comercialização de produtos e serviços diferenciados.

Segundo Csikszentmihalyi (1975), o "estado de fluxo" relaciona-se com a experiência vivida pelos indivíduos altamente motivados para a realização de atividades, sendo o envolvimento intenso e emocionante. Esse estado é atingido a partir da geração de componentes afetivos da motivação vinculados à concentração e às habilidades que se direcionam à execução de uma atividade. O consumidor/turista encontra-se em "estado de fluxo" quando a atividade desenvolvida encontra equilíbrio entre as habilidades do indivíduo e os desafios propostos na realização da tarefa (ARNOULD; PRICE, 1993; CARL III, 1994; CSIKSZENTMIHALYI, 1975). Para Pulido-Fernández e Navarro Hermoso (2014), as empresas turísticas devem criar produtos capazes de gerar experiências autênticas, prestando atendimento personalizado e de assessoria antes e durante a viagem, atentando para as expectativas, emoções, atitudes, valores e necessidades do cliente. Da mesma forma, os destinos turísticos precisam de mecanismos para mensurar as experiências dos turistas, e assim, convertê-las em conhecimento para o processo de gestão do turismo. De acordo com Ruiz e Gândara (2013, p. 276), esse cenário

justifica e viabiliza novas práticas políticas e ações integradas de planejamento, assim como algumas condições e oportunidades dos espaços urbanos tradicionais para atrair e fixar atores criativos e atividades inovadoras, enquanto se caracteriza a possibilidade de um desenvolvimento urbano competitivo.

Portanto, este estudo sobre produtos comercializados pelas agências de turismo receptivo em Curitiba pretende analisar, considerando a perspectiva dos gestores, se o que vem sendo comercializado por essas agências contempla todos os aspectos e dimensões mencionados. 


\section{TURISMO EM ANÁLISE}

Tourism in Analysis

\section{Metodologia}

Para este estudo, inicialmente, foi realizada uma revisão bibliográfica para o embasamento teórico, e depois definido o método para pesquisa de campo: entrevistas semiestruturadas em profundidade com empresários e/ou gestores de agências de turismo receptivo sediadas em Curitiba.

Quadro 1 - Modelo para análise de produtos criativos

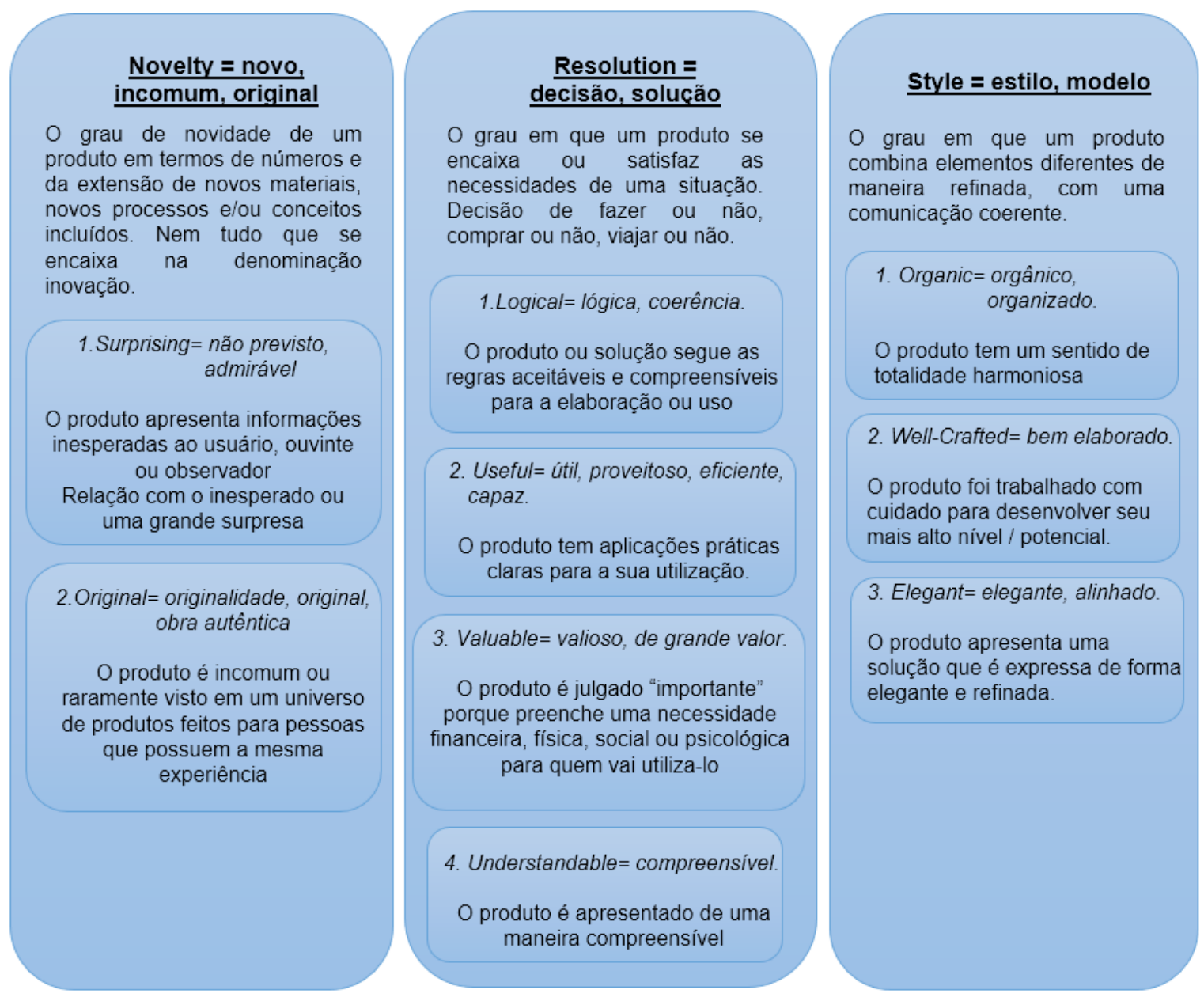

Fonte: Adaptado de Besemer e Treffinger (1981) e Besemer (1998).

Para obter os indicadores da pesquisa relacionados à criatividade e à inovação foi feita uma adaptação do modelo CPAM (BESEMER, 1998; BESEMER; TREFFINGER, 1981), que avalia a criatividade de produtos dentro das perspectivas apresentadas no Quadro 1. Cabe ressaltar que esse modelo foi escolhido por permitir analisar serviços considerando de forma conjunta as questões relacionadas a inovação e criatividade. 
Tourism in Analysis

O conjunto de indicadores utilizados para analisar a perspectiva da experiência de consumo do produto turístico foi baseado em dois modelos bastante utilizados em estudos anteriores. A Figural ilustra os conceitos da Economia da Experiência, de Pine II e Gilmore (1999).

Figura 1 - Dimensões da experiência

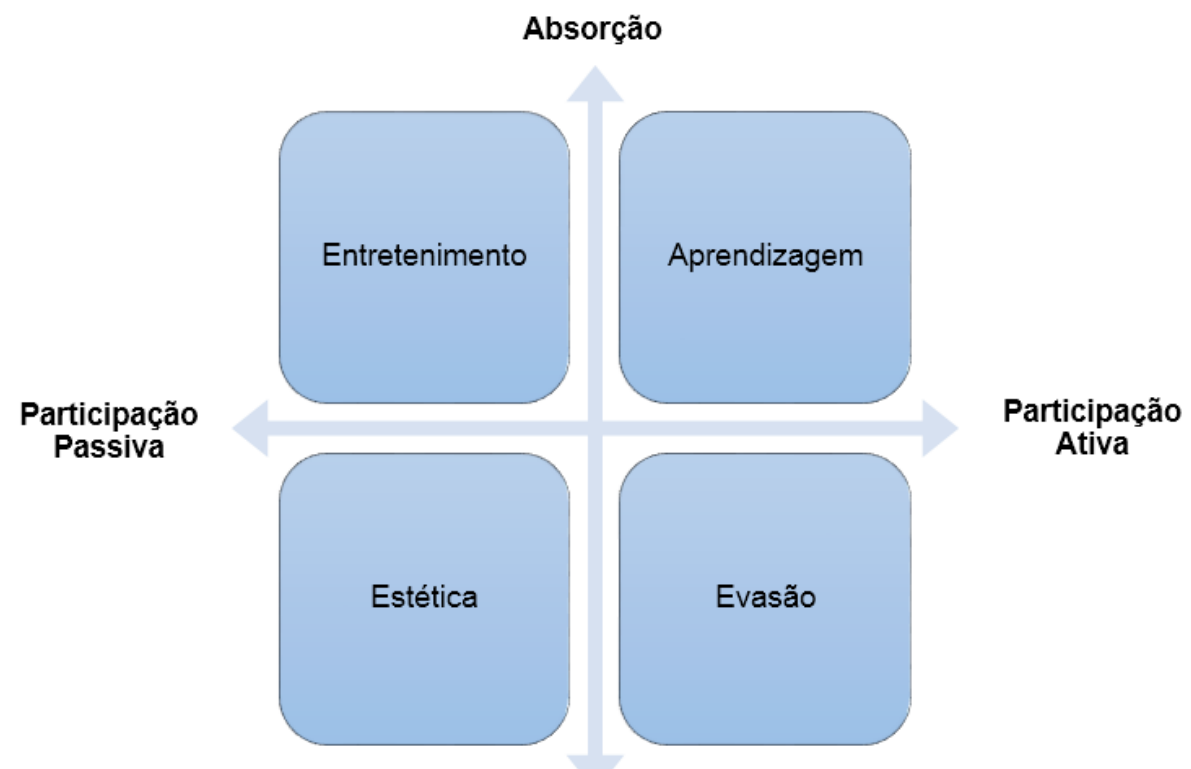

Imersão

Fonte: Adaptado de Pine II e Gilmore (1999).

Na mesma perspectiva, os elementos da Figura 2 complementam diferentes aspectos sociais, emocionais, sensoriais, criativos, relacionais, cognitivos e pessoais que conformam a experiência no consumo de produtos e serviços turísticos (PULIDO-FERNÁNDEZ; NAVARRO HERMOSO, 2014). 


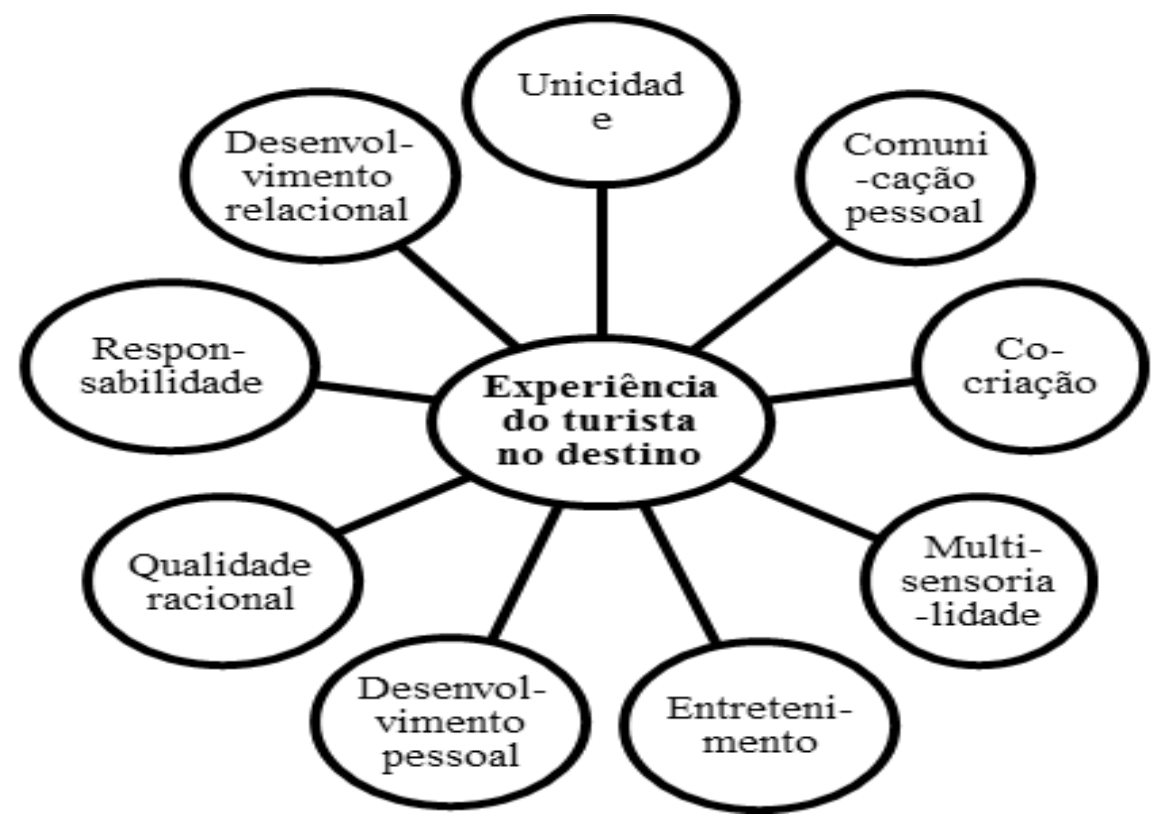

Figura 2 - Indicadores para medir a experiência do turista no destino

Fonte: Adaptado de Pulido-Fernández e Navarro Hermoso (2014). Tradução dos autores.

Para análise da perspectiva da emoção foi considerada a Teoria do Fluxo, de acordo com o Gráfico 1, que apresenta os principais aspectos relacionados a esse conceito, conforme destacado no marco teórico deste artigo:

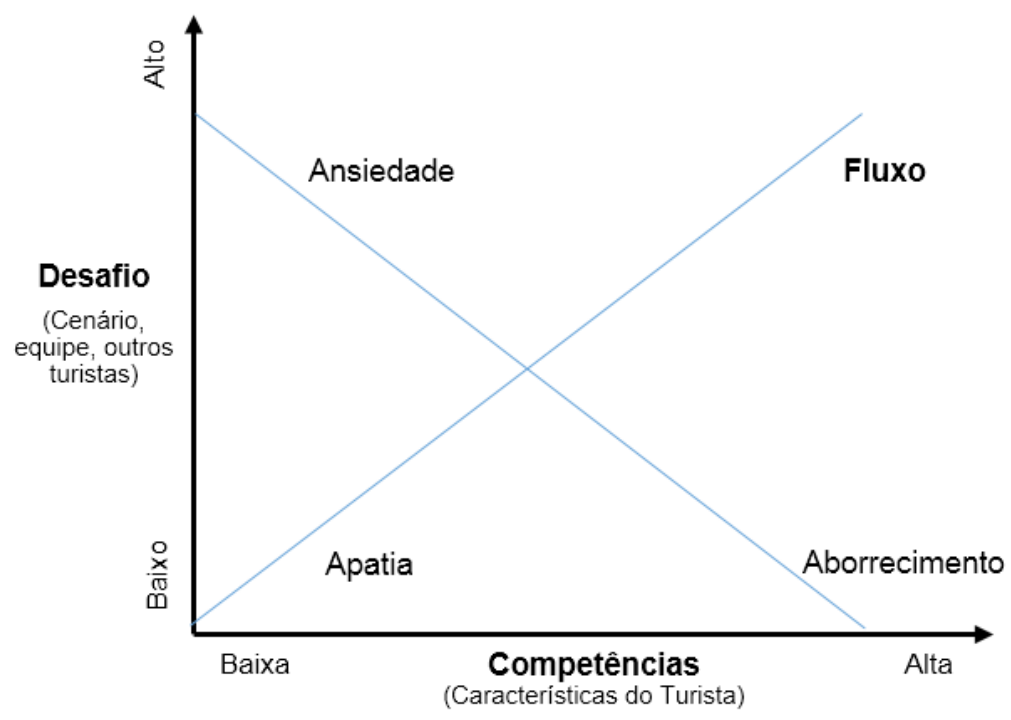

Gráfico 1 - Teoria do Fluxo

Fonte: Gândara et al.(2012), adaptado de Arnould e Price (1993), Carl III (1994) e Csikszentmihalyi (1975). 
A seleção dos entrevistados foi feita com base em pesquisa empírica e nas agências de turismo participantes do Núcleo de Turismo Receptivo de Curitiba ${ }^{3}$, que representa de forma organizada o setor de agências de receptivo de Curitiba desde 2008. Das quinze agências identificadas, onze atendiam ao critério de ofertar passeios turísticos em Curitiba e região (um dia de duração sem pernoite).

Antes do início das entrevistas foi feita uma pesquisa-piloto com um profissional atuante no mercado receptivo e com experiência acadêmica, dessa forma validando o instrumento de pesquisa sem alterações. As entrevistas foram realizadas com gestores (diretores/proprietários) de oito das onze agências de turismo receptivo que atendiam aos critérios previamente estabelecidos, já que algumas não responderam a nosso convite ou não demostraram interesse em responder à pesquisa. As agências de receptivo que participaram da pesquisa foram AH Turismo, Ivetur, Jens Tours, KuritBike, Onetur, Pinheiro Receptivo, Serra Verde Express e Special Paraná, no período de 14 de julho a 19 de agosto de 2014. Cabe ressaltar a relevância de tais agências no mercado de turismo receptivo de Curitiba e que todas autorizaram a divulgação dos respectivos nomes.

Todas as entrevistas foram realizadas pessoalmente pelos pesquisadores, e gravadas em áudio, também mediante autorização do entrevistado. A duração variou de uma a duas horas, pois os entrevistados ficaram à vontade para discorrer sobre as questões abordadas, podendo incluir temas relacionados, que inevitavelmente surgiram na conversação.

Após a coleta de dados foram feitas as transcrições das entrevistas gravadas em áudio, que totalizaram 337 páginas de conteúdo. Com base nesse material foi feita a codificação por meio de estrutura temática para organizar, selecionar e controlar o volume de conteúdo, com o intuito de acrescentar interpretação e teoria aos dados. Dessa forma, a codificação foi elaborada com os mesmos indicadores dos modelos teóricos utilizados na formulação do questionário da entrevista. Isso permitiu procurar padrões e estabelecer relações com os dados obtidos na pesquisa, permitindo a análise validação dos resultados por emparelhamento com o marco teórico construído para tal, assim como com estudos anteriores sobre temas afins.

\footnotetext{
3 O Núcleo recebe apoio e incentivo do Sebrae Paraná e do Curitiba, Região e Litoral Convention \& Visitors Bureau, para aprimorar e oferecer as melhores opções do segmento. As seis agências associadas são: AH Turismo, Jens Tours, KuritBike, Onetur, Serra Verde Express e Special Paraná (Dados retirados do site do Núcleo, disponível em: <http://www.receptivocuritiba.com.br/site_v4/index.php>. Acesso em: 1 ago. 2014).
} 
Tourism in Analysis

\section{Apresentação dos resultados}

$\mathrm{Na}$ entrevista foi perguntado quais são os produtos turísticos mais comercializados e também qual o produto referência em aspectos relacionados a criatividade e inovação, experiência e emoção, independente do volume de vendas. O Quadro 2 apresenta o resultado.

Quadro 2 - Principais produtos turísticos de Curitiba e região no enfoque de criatividade, inovação, experiência e emoção

\begin{tabular}{|c|c|c|c|c|c|}
\hline & $\begin{array}{l}\text { AGÊNCIAS DE } \\
\text { RECEPTIVO }\end{array}$ & $\begin{array}{l}\text { PRODUTO MAIS } \\
\text { COMERCIALIZADO }\end{array}$ & $\begin{array}{l}\text { PRODUTO REFERÊNCIA } \\
\text { EM CRIATIVIDADE E } \\
\text { INOVAÇÃo } \\
\end{array}$ & $\begin{array}{l}\text { PRODUTO } \\
\text { REFERÊNCIA EM } \\
\text { EXPERIÊNCIA } \\
\end{array}$ & $\begin{array}{l}\text { PRODUTO } \\
\text { REFERÊNCIA EM } \\
\text { EMOÇÃo } \\
\end{array}$ \\
\hline 1 & Ah Turismo & City-tour & Nenhum & Nenhum & Nenhum \\
\hline 2 & IVETUR & Ilha do Mel & $\begin{array}{l}\text { Vila Velha + Campo } \\
\text { Largo }\end{array}$ & Lapa & City-tour \\
\hline 3 & Jens TOURS & City-tour & Nenhum & Nenhum & Ilha do Mel \\
\hline 4 & KURITBIKE & $\begin{array}{l}\text { City-tour temático } \\
\text { (Coffee Bike Tour) }\end{array}$ & $\begin{array}{l}\text { City-tour temático } \\
\text { (Coffee Bike Tour) }\end{array}$ & $\begin{array}{l}\text { City-tour temático } \\
\text { (Coffee Bike Tour) }\end{array}$ & $\begin{array}{l}\text { Graciosa Bike } \\
\text { Tour }\end{array}$ \\
\hline 5 & ONETUR & Passeio de trem & Bynight Comedy Club & City-tour & $\begin{array}{l}\text { By-night tradi- } \\
\text { cional }\end{array}$ \\
\hline 6 & $\begin{array}{l}\text { PINHeIRo } \\
\text { RECEPTIVo }\end{array}$ & City-tour & Ilha do Mel & Ilha do Mel & Ilha do Mel \\
\hline 7 & $\begin{array}{l}\text { SERRA VERDE } \\
\text { EXPRESS } \\
\end{array}$ & Passeio de trem & Leva \& Traz & Passeio de trem & Passeio de trem \\
\hline 8 & $\begin{array}{l}\text { SPECIAL } \\
\text { Paraná }\end{array}$ & Passeio de trem & $\begin{array}{l}\text { Vila Velha + Carambeí } \\
+ \text { Castro }\end{array}$ & Passeio de trem & Ilha do Mel \\
\hline
\end{tabular}

Fonte: Os autores (2015).

Com base nos modelos selecionados e a partir dos indicadores estabelecidos previamente, foram estabelecidas perguntas buscando respostas que permitissem compreender as percepções de criatividade e inovação dos produtos comercializados pelos gestores das agências de turismo receptivo em Curitiba.

a. Unicidade: o produto é surpreendente (apresenta aspectos inesperados ao usuário)?

Para grande maioria dos gestores, a unicidade está vinculada ao atrativo/destino visitado e não a um diferencial do produto em si. No city tour o turista se surpreende com as belezas natural e construída da cidade, principalmente nas visitas aos parques. No passeio de trem, 
o próprio meio de transporte gera motivação, associado ao trajeto pela Serra do Mar, que é considerado um produto singular no Brasil. A KuritBike inovou na formatação do produto CoffeeBike Tour, já que não visita os atrativos turísticos tradicionais, mas oferece ao turista visitas a cafeterias, com degustação de cafés especiais, além de surpreendê-lo com uma abordagem aprofundada sobre a cultura do café.

b. Originalidade: o produto é original (incomum ou criativo)?

A KuritBike ressaltou a criatividade do CoffeeBike Tour, considerado inédito no Brasil, e provavelmente no mundo neste formato, segundo seu gestores. O proprietário declarou que a missão da empresa é ter produtos novos e criativos para mostrar uma cidade dinâmica e atual. Outros representantes de agências comentaram que alguns atrativos são incomuns quando comparados a outros destinos, e, por isso, o produto acaba se tornando original. A Serra Verde Express, por exemplo, utiliza o trem e o trajeto pela Serra do Mar como o principal recurso na formatação do produto. Além do produto mais comercializado, a maioria dos entrevistados identificou outros mais criativos, que se caracterizam por explorar diferentes locais com potencial turístico. Muitas vezes é a combinação de atrativos conforme o perfil do cliente que torna o produto incomum, ou seja, conformado buscando atender às demandas específicas.

c. Coerência: o produto é coerente (adequado às expectativas do consumidor)?

Grande parte dos representantes das agências afirmou que seu produto deixa o turista satisfeito e muitas vezes supera as expectativas. Isso acontece pelo atendimento privativo, que permite ser mais coerente com as necessidades do cliente, e também está relacionado à informação que o turista tem, impactando positivamente na experiência. A KuritBike confirma isso quando o turista imagina que vai apenas pedalar por cafeterias e degustar cafés, mas o aprendizado sobre a bebida e a imersão no tema o surpreendem. O mesmo ocorre quando o turista espera apenas fazer um passeio de trem e desfrutar da paisagem, e não imagina que na sequência irá visitar Morretes e Antonina e conhecer a gastronomia local. Por outro lado, a Special Paraná destacou que esse produto não é coerente devido ao preço cobrado e à estrutura/conforto disponível no trem, considerando principalmente o público estrangeiro.

d. Utilidade: o produto é útil e eficiente (o turista percebe a utilidade do produto ao consumi-lo)? 
O city tour foi considerado eficiente para conhecer as principais atrações turísticas da cidade, dentro da limitação de tempo disponível (média de quatro horas). São oferecidos opcionais para conhecer lugares não contemplados no roteiro, mas geralmente os turistas fazem essas visitas por conta própria. O representante da $\mathrm{AH}$ Turismo ressaltou que um guia credenciado na condução do passeio permite ao turista conhecer a cidade de uma maneira mais completa e mais eficiente. Sobre o passeio de trem, que tem a Serra do Mar como destaque, o entrevistado da Onetur comentou a utilidade do passeio ao permitir a contemplação da natureza de duas formas: na ida, pela ferrovia, no percurso de trem, e na volta, pela Estrada da Graciosa, com parada no mirante.

e. Importância: o produto é julgado pelo turista como importante/necessário?

Percebeu-se a preocupação das agências em valorizar o produto e mostrar para o cliente a importância dele. A Ivetur pratica isso antes mesmo da chegada do turista no destino, por meio de atendimento personalizado e envio de informações. O representante da Pinheiro Receptivo ressaltou a experiência e o conhecimento sobre o produto e o quanto a orientação sobre passeios e restaurantes na Ilha do Mel interferem na qualidade da visitação. A Serra Verde Express observou uma necessidade e a transformou em oportunidade de mercado, já que o Leva e Traz é um produto único no Brasil nesse formato, que proporciona facilidade e comodidade de transporte gratuito para o turista ir à noite a bares, restaurantes, casas de show, teatros e shoppings associados.

f. Compreensão: o turista tem informações suficientes para compreender o produto e usufrui-lo?

Com a atual possibilidade de amplo acesso à internet muitos turistas obtêm informações sobre locais e opções de passeios turísticos com antecedência. Alguns também têm conhecimento prévio por indicações e recomendações de amigos e parentes. Todavia, as agências foram unânimes em considerar que durante a realização dos passeios a maior fonte de informações é o guia de turismo. Apesar de existir um roteiro pré-definido, o guia tem autonomia no enfoque da abordagem, conforme sua especialidade e interesses do grupo. Esse é o grande diferencial do city tour, pois o guia acompanha o grupo durante todo o passeio, e pode oferecer informações importantes e necessárias para o turista usufruir e conhecer melhor a cidade. De todos os produtos mencionados, nenhum oferece um guia local do atrativo para 
atendimento e orientações ao turista, o que reforça ainda mais a importância da assessoria do guia de turismo na condução dos passeios.

g. Harmonia: o produto ofertado é realizado em seu conjunto conforme planejado e de forma harmônica?

Os representantes das agências comentaram que, na maioria das vezes, os clientes realizam os passeios da forma proposta pela confiabilidade em buscar uma empresa especializada e com experiência. Os entrevistados ressaltaram que a flexibilidade tem certas limitações, pois no passeio à Ilha do Mel, por exemplo, existem horários pré-definidos de saídas dos barcos e o guia precisa monitorar o tempo para não arriscar perder esse transporte. No passeio de trem também existem horários fixos de saída, que podem ainda sofrer interferências da via quando o trem de passageiros tem de aguardar e dar prioridade ao trem de carga. Nesse caso o atraso pode ser bem significativo, e o guia terá de reduzir o tempo em Antonina ou Morretes para não interferir no horário previsto para retorno a Curitiba.

h. Potencialidade: o produto foi elaborado da melhor maneira possível para aproveitar todo seu potencial?

Tratando-se de Curitiba, o entrevistado da AH Turismo considerou que o ideal seria um city tour de oito horas para aproveitar melhor o potencial da cidade, mas isso fugiria do padrão de mercado, que em qualquer cidade do mundo trabalha com city tour de quatro horas, em média. Essa padronização do produto, segundo o representante da Jens Tours, faz que não se ofereça nada de diferente ou surpreendente ao turista. A Serra Verde Express e a Onetur tomaram várias iniciativas de explorar mais o potencial do litoral e criar combinações com o trem, mas encontraram dificuldade para conseguir demanda suficiente, considerando a sazonalidade e parcerias que viabilizassem boas condições de preço.

i. Adequação: o produto é adequado às características e perfil do consumidor?

Como a maioria das agências oferece serviços privativos, previamente o produto pode ser ajustado e direcionado conforme o perfil do cliente e, ainda, o guia pode personalizar a realização do passeio para que o turista tenha uma experiência satisfatória de visitação no destino. Isso é relevante quando se compara, por exemplo, um grupo de terceira idade com um grupo de estudantes, que exigem ritmo e dinâmica diferenciados. Quanto ao padrão e categorias de serviço, conforme o poder aquisitivo, o cliente pode realizar o city 
tour em um carro executivo ou contratar o passeio de trem na litorina de luxo ou no vagão de classe econômica, por exemplo.

Na sequência são apresentadas, a partir de alguns indicadores estabelecidos previamente, as percepções dos gestores com relação à experiência com os produtos comercializados pelas agências de turismo receptivo em Curitiba.

a. Evasão: o produto faz que o turista consiga desprender-se do cotidiano?

Os passeios caracterizam-se por atividades de lazer que envolvem visitas a lugares que estimulam o turista a despreocupar-se do cotidiano. No city tour os turistas ficam admirados, a cada parada, com as belezas naturais dos parques, e no passeio de trem, distraem-se com a observação da paisagem e a expectativa de ver novas atrações no percurso. De maneira geral, a paisagem natural é o grande fator de evasão nos produtos identificados.

b. Entretenimento: o produto proporciona entretenimento?

Alguns gestores entrevistados justificaram que os passeios não proporcionam entretenimento por serem mais contemplativos, enquanto outros associaram esse aspecto à forma de atuação mais divertida e descontraída do guia de turismo. Alguns destacaram que a beleza paisagística dos atrativos não demanda atividades complementares de entretenimento dos turistas.

c. Aprendizagem: o produto gera possibilidades de aprendizagem e desenvolvimento pessoal?

A aprendizagem do turista durante os passeios está muito vinculada ao papel do guia de turismo, que, além de credenciado, precisa ter experiência e estar bem preparado para atender e orientar o grupo. Além do guia, a própria percepção da cidade (organização urbana, limpeza, transporte público, educação no trânsito) gera aprendizagem para o turista.

d. Estética: o produto promove momentos de contemplação (permite desfrutar da beleza do entorno natural ou construído)?

Todos os passeios permitem momentos de contemplação dos patrimônios naturais e culturais a eles relacionados. Cada turista tem um olhar diferente, conforme parâmetros em relação à cidade onde mora e a suas experiências de viagem. Os passeios promovem contemplação durante todo o período de realização, já que no city tour tradicional são feitas visitas panorâmicas (sem parada) durante o trajeto. No CoffeeBike Tour o trajeto feito de bicicleta por 
Tourism in Analysis

ciclovias já propicia outra percepção da cidade, e o trem combina a beleza natural (trajeto do trem) e a beleza construída (Morretes e Antonina).

e. Comunicação social: o produto motiva o turista a compartilhar suas experiências com outras pessoas?

Com o amplo uso das redes sociais, o compartilhamento de mensagens e imagens pode acontecer ao mesmo tempo em que o turista esteja vivenciando a experiência. No entanto, no passeio de trem em alguns momentos não há sinal para acesso a redes por celular, e observa-se que isso estimula uma interação maior entre as pessoas, no grupo e com outros turistas. Após realizar os passeios essa comunicação continua pelo contato com outros turistas, amigos e familiares.

f. Responsabilidade: este produto está relacionado a alguma ação sustentável com a sociedade e o meio ambiente?

De maneira geral, os aspectos de responsabilidade e sustentabilidade estão mais voltados para as ações do destino/atrativo do que para o produto/empresa em si. No city tour em Curitiba destaca-se que a cidade é pioneira na reciclagem, no cuidado com o meio ambiente e áreas verdes, e na limpeza (educação do curitibano sobre o lixo). No passeio de trem é feita uma sensibilização para preservação da Mata Atlântica, conscientização sobre o lixo e impactos positivos na economia de Morretes e Antonina. No entanto, a KuritBike destaca-se por oferecer passeios apenas de bicicleta, que já reflete um meio de transporte mais sustentável, e o representante da Serra Verde Express comentou que a empresa pratica ações sustentáveis e projetos de responsabilidade social, dos quais o turista não toma conhecimento.

A partir de alguns indicadores estabelecidos previamente, são apresentadas a seguir as percepções dos gestores sobre da emoção proporcionada pela ação dos produtos comercializados pelas agências de turismo receptivo em Curitiba.

a. Participação ativa: o produto estimula uma participação ativa do turista de acordo com seu perfil e interesses?

A maioria dos passeios segue um roteiro-padrão, mas alguns oferecem uma oportunidade de participação mais ativa do turista. Na Ilha do Mel, o turista tem mais tempo e liberdade para realizar atividades de sua preferência (caminhada, praia, bicicleta, lancha etc.). Após o passeio de trem, o turista também pode escolher uma programação diferenciada em vez de 
seguir a programação básica de visitar Morretes e Antonina - mas depende de uma solicitação prévia para a operadora.

b. Cocriação: o produto oferece a possibilidade de personalização e adaptação, durante sua realização, conforme o perfil e motivação dos turistas?

O guia é o grande responsável por ajustar o produto ao perfil e motivação dos turistas durante a realização do passeio, dentro de algumas limitações. No caso de um city tour privativo, por exemplo, o grupo pode definir os locais e o tempo de parada nos atrativos, mas quando se atende um grupo heterogêneo é necessário seguir a programação-padrão. A maior parte dos produtos exige que a personalização seja planejada com antecedência, no momento da contratação do passeio, já que muitas atividades dependem de reserva de espaços e contratação de profissionais. Por isso, depende da iniciativa da agência estimular a cocriação e oferecer opcionais que atendam da melhor forma a necessidades e expectativas do cliente.

c. Desenvolvimento pessoal e relacional: o produto estimula uma interação construtiva e enriquecedora do turista com a população local, com outros turistas e com a equipe do receptivo?

Pela limitação de tempo, o contato do turista durante os passeios acontece mais com a equipe do receptivo e com o próprio grupo. O produto não cria oportunidades/atividades propícias de interação com a comunidade local, apenas acontece rapidamente no comércio local em Morretes e na Ilha do Mel. Em contrapartida, no CoffeeBike Tour existe um contato maior com os funcionários e proprietários das cafeterias, que recebem e se relacionam diretamente com o turista. No Bike Tour Graciosa o estímulo ao desenvolvimento pessoal e relacional é intenso, pela interação e colaboração no grupo para realizar o trajeto (apoio físico e moral), e pelo incentivo ao contato com a população e à degustação de produtos locais.

d. Multissensorialidade: o produto proporciona uma experiência multissensorial (sentidos, sentimentos, pensamentos, comportamentos etc.)?

Nesse aspecto cada turista tem um comportamento diferenciado, seja pelo ambiente e beleza natural (visão e olfato) e pela gastronomia (paladar), seja pela sensação de bem-estar. Cabe ressaltar que nos aspectos abordados anteriormente a individualidade é relevante, porém, no tocante à multissensorialidade, ela se faz ainda mais forte. Como exemplos, o entrevistado da Jens Tours comentou que na Ilha do Mel o turista tem uma ligação mais próxima com a 
natureza, sem interferências urbanas (carros, som), em um ambiente mais rústico, que estimula hábitos diferentes do cotidiano. No city tourem Curitiba algumas agências incluem a visita ao Jardim das Sensações, dentro do Jardim Botânico, que possibilita ao visitante ter contato com as texturas, formas e aromas de plantas, inclusive com os olhos vendados. $\mathrm{O}$ representante da KuritBike ressaltou que um passeio realizado de bicicleta remete a memórias de infância e sentimentos de superação, e a degustação nas cafeterias remete ao prazer da bebida e da descoberta.

e. Racionalidade: a racionalidade (preços acessíveis/facilidades de pagamento/hospedagem adequada/logística de transporte) interfere na experiência do turista nesse produto? A maioria dos entrevistados não observou dificuldades relevantes que interfiram na realização dos passeios ou na experiência do turista. Quando existe um atraso no trajeto do trem, por exemplo, os guias têm autonomia para adaptar a programação; quando o clima não está favorável para o city tour, os guias também podem substituir por algumas visitas em locais fechados. Alguns turistas reclamam do preço de alguns produtos, mas sem levar em conta os serviços oferecidos ou sem considerar que não existe cobrança de ingressos em nenhuma das atrações do city tour, por exemplo. Foi destacado que, geralmente, depois da realização dos passeios, os turistas consideram que a relação qualidade-preço é satisfatória. O representante da Pinheiro Receptivo considerou que o horário de abertura dos parques deveria ocorrer mais cedo para otimizar a programação do passeio.

\subsection{Discussão dos resultados}

Ao definir os produtos-referência em cada critério, descritos no Quadro 2, os representantes das agências de turismo pesquisadas demonstraram nas justificativas o que julgam ser um produto que contempla criatividade, inovação, experiência e emoção.

Os produtos comercializados pela $\mathrm{AH}$ Turismo são tradicionais e não contemplam aspectos criativos e inovadores, por serem similares aos de outras empresas no mercado. Para o gestor da empresa, o city tour e o passeio de trem são os produtos mais importantes de Curitiba, e, por isso, proporcionam a melhor experiência de visitação. No entanto, conforme tratado em estudos anteriores, as necessidades dos consumidores e as habilidades dos concorrentes 
mudam constantemente, fazendo que no processo contínuo de comercialização de produtos, novos ou já existentes, as adaptações de componentes sejam necessárias para suprir estas transformações (MIDDLETON; CLARKE, 2002).

A Ivetur defendeu a criatividade do produto Vila Velha + Campo Largo, justamente por combinar um atrativo turístico tradicional (Vila Velha) com opcionais personalizados de acordo com o interesse e perfil do turista, que podem ser uma visita a uma fábrica de porcelana, a uma fazenda na região dos Campos Gerais ou a uma cervejaria. As regiões mais próximas a Curitiba, como os Campos Gerais e a Região Metropolitana, exploram muito o turismo rural associado aos atrativos naturais, com chácaras, pousadas e restaurantes para receber o turista, elementos destacados como importantes no marco teórico (BAHL; NITSCHE, 2012). $\mathrm{Na}$ dimensão da experiência, a entrevistada da Ivetur ressaltou o apelo cultural e histórico da cidade da Lapa, que já foi um produto muito vendido quando existia uma linha de trem que a ligava a Curitiba. Segundo a gestora, atualmente é um destino visitado principalmente por grupos de estudantes, mas carece de maior divulgação, justamente por sua importância histórica para o Paraná. No que se refere à questão da emoção, ela ressaltou o city tour, pela satisfação e encantamento do turista ao conhecer os famosos parques da cidade, que tem uma enorme diversidade e riqueza cultural. Uma peculiaridade dos parques urbanos de Curitiba é a homenagem e a valorização dos diversos grupos étnicos que compõem a população multicultural, aspecto ressaltado no marco teórico (BAHL, 2004).

Assim como a AH Turismo, a Jens Tours também opera os passeios tradicionais de receptivo em Curitiba, e não se considerou criativa, por não ter nenhum produto exclusivo ou diferenciado em relação à concorrência. $\mathrm{O}$ city tour, seu produto mais vendido, contempla os indicadores da experiência, mas o entrevistado da Jens Tours acredita que o produto poderia melhorar nesse aspecto. Em relação à emoção, a Ilha do Mel foi mencionada por permitir mais autonomia, liberdade e diversidade de atividades para o turista interagir com o local. Nessa conjuntura, as discussões realizadas em estudos anteriores permitiram compreender que o conceito de "produto" tem evoluído para "experiência e entretenimento", voltado para a vivência do cliente com o produto/serviço (HINOJOSA, 2015). Além dele, evoluem outros elementos do mix de marketing, como "pessoas" representando as integrações sociais, e "psicologia" dentro de conceitos contemporâneos das experiências e emoções, no processo de compra e consumo de produtos (MORRISON, 2012). 
A KuritBike foi a única de todas as agências pesquisadas que afirmou ter seu produto mais criativo e inovador, o produto mais comercializado. Segundo o entrevistado da empresa, o CoffeeBike Tour abriu uma nova geração de roteiros criativos, fazendo que a KuritBike deixasse de apenas locar bicicletas ou operacionalizar passeios tradicionais nos parques. $\mathrm{O}$ intuito é inovar, principalmente com roteiros temáticos e contemporâneos.

Conforme ressaltado em outros estudos sobre a mesma temática, esse é o panorama do turismo criativo, em que as empresas exploram aspectos da participação ativa e aprendizagem do turista na cocriação de sua experiência, gerando conhecimento e promovendo o desenvolvimento pessoal (RICHARDS; WILSON, 2006). Nesse sentido, a KuritBike também oferece o Bike \& Bar, um roteiro noturno que mostra a diversidade de bares e gastronomia, em um contexto cultural genuinamente curitibano. A ideia é mostrar que Curitiba supera a tradição do bairro italiano de Santa Felicidade nesse aspecto. E tratando do item emoção, o passeio Bike Graciosa + Trem destacou-se, tanto por combinar dois grandes atrativos (Serra do Mar e trem) como por ser mais ativo e interativo, em função do tempo maior de pedalada e do contato com a natureza. Assim, como tratado no marco teórico, se propicia aos turistas sentir o "estado de fluxo", pois a atividade desenvolvida encontra equilíbrio entre as habilidades do indivíduo e os desafios existentes naquele momento (ARNOULD; PRICE, 1993; CARL III, 1994; CSIKSZENTMIHALYI, 1975).

Dentro de sua variedade de produtos, a Onetur sugeriu um para cada elemento de análise. $\mathrm{O}$ Bynight Comedy Club foi um produto criado exclusivamente pela empresa, e transformou-se em sucesso de vendas. A justificativa está na inovação da própria cidade, que oferece muitos locais e atrativos a serem explorados e comercializados. Assim como a KuritBike, a intenção da Onetur é mostrar outros polos gastronômicos em Curitiba além de Santa Felicidade, um dos grandes atrativos do tradicional Bynight. Portanto, de acordo com discussões anteriores realizadas sobre essa questão, cabe ao profissional ser um travel design na elaboração de roteiros, pensando na distribuição espaço-temporal dos atrativos, e conduzindo o olhar do turista para a essência do destino (GASTAL, 2012). Segundo o gestor da Onetur, o turista gosta de novidade e, por isso, a agência já lançou outros produtos, como Passeio de Compras, Esporte Tour, Curitiba Sustentável, entre outros. Para alcançar essa valorização de Curitiba, a Onetur indicou o city tour como um fator de experiência e emoção para o turista, relacionado aos atrativos e aspectos sustentáveis da cidade, seja de dia ou de noite, com o 
Bynight. Para Wong e Mckercher (2012), de acordo ao identificado em estudos anteriores, roteiros turísticos locais representam uma parte importante da prestação de serviços voltada para a experiência turística em um destino.

A Pinheiro Receptivo é especialista em produtos para o litoral, principalmente Ilha do Mel, apesar de o city tour ter um maior volume de vendas. Por esse motivo, considera a Ilha do Mel como um produto criativo pela forma de sua operacionalização, e também observou o impacto do local na experiência e emoção do turista. $\mathrm{O}$ entrevistado garantiu que, pela experiência proporcionada pelo produto, ocorre a satisfação do turista, principalmente pelo contato com a natureza e todos os atrativos visitados ao longo da programação. A Ilha do Mel, conforme discutido em estudos anteriores, é um destino visitado por turistas nacionais e internacionais, que buscam, além das praias, um contato maior com a natureza protegida e preservada, em um ambiente simples e rústico (TELLES; GÂNDARA, 2012).

O principal produto da Serra Verde Express é o próprio passeio de trem, amplamente divulgado e conhecido no Brasil e no exterior, e comercializado por todo o mercado turístico, aspecto já ressaltado em estudos anteriores (TONON, 2014). Nele sobressai a Serra do Mar, onde está a maior área preservada de Mata Atlântica do Brasil, que pode ser contemplada por turistas ao longo da ferrovia, e no retorno do passeio ao longo da Estrada da Graciosa. Esse conteúdo natural, associado ao conhecimento e tradição na operacionalização do passeio, permite atingir as dimensões da experiência e da emoção, deixando o turista satisfeito. Por outro lado, a empresa se preocupa com inovação e cria opções diferenciadas para o passeio de trem, permitindo ao turista personalizar a experiência conforme interesses. O produto Leva $\&$ Traz foi indicado pelo entrevistado como o mais criativo, por ser um serviço único e exclusivo no Brasil, que atende à necessidade do turista e integra a agência com outras empresas do trade turístico (hotéis, restaurantes e estabelecimentos comerciais). De maneira geral, como abordado no marco teórico, a inovação depende dos objetivos da empresa e dos fatores que interferem no processo e na produção, conduzidos pelas práticas de marketing e pela busca da qualidade e da satisfação de clientes e da equipe de trabalho (WEIERMAIR, 2004).

Assim como a Ivetur, a Special Paraná optou por inovar em produtos com características regionais, que integram Curitiba e a região dos Campos Gerais, destacando, principalmente, os atrativos e a cultura holandesa em Castrolanda e Carambeí, que surpreendem positivamente o turista. Estudos anteriores destacam que a intenção do Programa Nacional de Regionalização 
do Turismo é definir roteiros turísticos que possam ser convertidos em produtos competitivos e de qualidade, a partir da composição de elementos da natureza, sociedade e cultura local, com o suporte de infraestrutura e equipamentos adequados (ABAV; SEBRAE, 2010; BAHL; NITSCHE, 2012). Entretanto, para gestora da Special Paraná, como a experiência e a emoção são muito individuais, cada produto pode causar diferentes impactos, especialmente o passeio de trem, na experiência, e a Ilha do Mel, na emoção.

De maneira geral, como foi possível compreender, segundo os gestores os produtos mais comercializados pelas agências de receptivo são justamente os mais conhecidos e que contemplam as principais atrações turísticas de Curitiba e região. Dessa forma, são considerados importantes e necessários para o turista, seja o city tour, que representa o primeiro contato com a cidade, seja o passeio de trem Curitiba/Litoral, que consta entre as dez melhores atrações turísticas do Brasil em guias impressos internacionais.

O city tour destaca-se como o produto, tanto tradicional quanto temático, que proporciona a melhor experiência ao turista, valorizando o patrimônio natural e cultural da cidade. No que se refere à questão da emoção, destaca-se a natureza da região do litoral paranaense, com os passeios para Ilha do Mel e Serra do Mar. Dessa forma, como discutido em estudos anteriores, percebe-se o interesse das agências em atender o público com diversas opções para proporcionar ao turista a melhor experiência de visitação, com produtos inovadores e voltados para interação emocional e vivência no destino (PAZINI et al., 2014).

Por outro lado, a maioria dos entrevistados identificou que os passeios mais vendidos não são os mais criativos e inovadores, e também não permitem vivenciar diretamente as dimensões da emoção. Reconheceram, no entanto, ter condições de proporcionar uma experiência de qualidade na visitação, já que consideraram o produto mais vendido como referência em experiência. Cabe ressaltar que, no cenário das experiências, muitas vezes o turista também faz uma viagem interior, ou seja, para dentro de si mesmo, devido à maneira com que percebe o lugar, o povo e o impacto que essa percepção subjetiva proporciona (CARBALLO FUENTES et al., 2015). Por isso, os aspectos emocionais são considerados uma forma de também enriquecer a experiência turística nos destinos, considerando a subjetividade individual e a necessidade de proporcionar emoções positivas ao turista (GÂNDARA et al., 2012).

Fazendo uma análise dos diversos produtos mais criativos e inovadores de todas as agências de turismo receptivo pesquisadas, o principal critério de diferenciação foi a exclusividade, 
ou seja, são aqueles produtos únicos, que não são vendidos por outras agências no mercado, ou porque se desenvolvem de forma personalizada ou porque são conformados buscando que sejam consumidos de forma diferenciada. No entanto, percebeu-se que, embora muitas agências elaborem produtos novos e opcionais para personalizar a experiência do turista, na maioria das vezes o produto clássico tem uma adesão maior.

A pesquisa detectou que os produtos considerados mais criativos também são inovadores por buscarem valorizar os atrativos turísticos com maior potencial, tendo presente o conceito de inovação de produto, processo, gestão e comercialização, e não apenas de "fazer coisas novas". Dessa maneira, destaca-se a região dos Campos Gerais, onde, segundo comentário da representante da Special Paraná, ainda existem locais pouco explorados. O entrevistado da Onetur ressaltou o potencial de Curitiba como cidade inovadora e dinâmica, que permite a criação e exploração de novos produtos para aumentar o consumo da oferta turística. Christensen (1999) salienta que a chave do conceito de criatividade para o processo de inovação encontra-se relacionada com a forma de encontrar ideias para novos produtos e serviços únicos e valorizados nos mercados nos quais serão comercializados.

\section{Considerações finais}

De acordo com os resultados da pesquisa, na maioria das vezes os produtos mais comercializados pelas agências não são os mais criativos, pois o volume de vendas dos produtos mais tradicionais acaba sendo maior, como o city tour, por exemplo - que é normalmente incluído nos pacotes turísticos para que o turista conheça os principais atrativos da cidade. Mesmo inserida nesse contexto de mercado, destaca-se a KuritBike, que apresentou um perfil de empresa inovadora, por realizar todos os passeios de bicicleta e por oferecer roteiros diferenciados, como o de degustação em cafeterias. Segundo o entrevistado, faz parte da missão da empresa oferecer produtos novos e explorar mercados inéditos, cujo objetivo é criar uma demanda exclusiva para seu produto.

De maneira geral, notou-se por parte de todas as agências de turismo receptivo de Curitiba a preocupação em satisfazer e superar a expectativa dos clientes, buscando ajustar o produto a seu perfil e interesses. Nesse sentido, reforçando a importância e atualidade do conceito 
de cocriação e o papel do guia nesse "processo", identificou-se que o acompanhamento do guia é fundamental para perceber as motivações do grupo, fazer os ajustes possíveis e necessários, e ser uma fonte de informações e aprendizado nesse processo de interação. Também foi possível identificar que, no caso dos produtos das agências de receptivo de Curitiba, se oferecem muitos momentos de contemplação e evasão, relacionados ao contato com a natureza e pelas características dos atrativos. Esses aspectos geralmente permitem ao turista vivenciar experiências e emoções particulares e de qualidade, desde que o passeio se ajuste a sua realidade e preferências.

Desse modo, compreende-se a inter-relação entre as experiências e as emoções, pois "o turista contemporâneo deseja deslocar-se para destinos onde possa mais que contemplar, viver e emocionar-se, ser o personagem de sua própria viagem. Ele anseia envolver-se nas experiências" (GÂNDARA;GIMENES;MASCARENHAS, 2009, p. 187).

Esta pesquisa pretende colaborar com o mercado de turismo receptivo, trazendo uma percepção e uma oportunidade de reflexão sobre o que está sendo oferecido de criativo e inovador nos serviços, na experiência proporcionada ao turista e no mercado potencial a ser explorado. Nesse sentido, estudos complementares com turistas que realizaram os passeios mencionados podem colaborar com uma nova percepção desses elementos para uma análise comparativa entre a oferta e a demanda.

\section{Referências}

AMABILE, T. M.A model of creativity and innovation in organizations. Research in Organizational Behavior, Bingley, v. 10, n. 1, p. 123-167, 1988.

AMABILE, T. M. et al. Assessing the work environment for creativity. Academy of Management Journal, New York, v. 39, n. 5, p. 1154-1184, 1996.

ARNOULD, E.; PRICE. L. River magic: extraordinary experience and the extended service encounter. Journal of Consumer Research, Oxford, v. 20, n. 1, p. 24-45, 1993.

ABAV - Associação Brasileira de Agências de Viagens; SEBRAE - Serviço de Apoio às Micro e Pequenas Empresas. Estratégias de marketing para agências de turismo receptivo. 2010.

ASTORINO, C. Agências e serviços receptivos. In: BRAGA, D. C. (Org.). Agências de viagens e turismo: práticas de mercado. Rio de Janeiro: Elsevier, 2008. 
Tourism in Analysis

BAHL, M. Viagens e roteiros turísticos. Curitiba: Protexto, 2004.

BAHL, M.; NITSCHE, L. B. Roteiros e itinerários turísticos como elementos dinâmicos no desenvolvimento regional do turismo. In: RAMOS, S. P. (Org.). Planejamento de roteiros turísticos. Porto Alegre: Asterisco, 2012.

BESEMER, S. P. Creative product analysis matrix: testing the model structure and a comparison among products-three novel chairs. Creativity Research Journal, v. 11, n. 4, p. 333-346, 1998.

BESEMER, S. P.; TREFFINGER, D. J. Analysis of creative products: review and synthesis. Journal of Creative Behavior, Malden, v. 15, n. 3, p. 158-178, 1981.

BRAGA, D. C. Discussão conceitual e tipologias das agências de turismo. In: BRAGA, D. C. (Org.). Agências de viagens e turismo: práticas de mercado. Rio de Janeiro: Elsevier, 2008.

CANANI, I. S. S. Guia de turismo: o mérito da profissão. Turismo em Análise, São Paulo, v. 10, n. 1, p. 92-106, 1999.

CARBALLO FUENTES, R. et al. La creación y promoción de experiencias en un destino turístico: un análisis de la investigación y necesidades de actuación. Cuadernos de Turismo, n. 35, p. 71-94, 2015.

CARL III, W. J. Flow: A theory of optimal experience: history and critical evaluation. 1994. Disponível em: <http://bit.ly/2gvniu7>. Acesso em: 11 maio 2013.

CHRISTENSEN, C. M. Innovation and the General Manager. Boston: Irwin McGraw-Hill, 1999.

CROPLEY, D. H.; KAUFMAN, J. C.; CROPLEY, A. J. Measuring creativity for innovation management. Journal of Technology Management \& Innovation, v. 6, n. 3, p. 13-30, 2011.

CSIKSZENTMIHALYI, M. Beyond boredom and anxiety: the experience of play in work and games. San Francisco: Jossey-Bass Publishers, 1975.

GÂNDARA, J. M. G. et al. Planificación estratégica de un circuito turístico histórico-cultural experiencial: Itabuna - Bahia, Brasil. Estudios y perspectivas en turismo, Buenos Aires, v. 21, n. 1, p. 225-248, 2012.

GÂNDARA, J. M. G.; GIMENES, M. H. S. G.; MASCARENHAS, R. G. Reflexões sobre o Turismo Gastronômico na perspectiva da sociedade dos sonhos. In: PANOSSO NETTO, A.; ANSARAH, M. G. R. (Orgs.). Segmentação do mercado turístico: estudos, produtos e perspectivas. Barueri: Manole, 2009. 
Tourism in Analysis

GASTAL, S. Turismo e cultura: aproximações e conflitos. In: BENI, M. C. (Org.) Turismo: planejamento estratégico e capacidade de gestão - desenvolvimento regional, rede de produção e clusters. Barueri: Manole, 2012.

GIMENES, M. H. S. G., BIZINELLI, C.; MANOSSO, F. C. Enoturismo e atividades complementares: estratégias para a maximização da experiência turística. In: IX SEMINÁRIO DA ASSOCIAÇÃO NACIONAL PESQUISA E PÓS-GRADUAÇÃO, 9., 2012, São Paulo. Anais... São Paulo: Universidade de São Paulo, 2012.

HANER, U.-E. Spaces for creativity and innovation in two established organizations. Creativity and Innovation Management, Malden, v. 14, p. 288-298, 2005.

HINOJOSA, V. Evolución del marketing hotelero: de las cuatro P a las cuatro E. Hosteltur, 26 jan. 2015. Disponível em: <http://bit.ly/1Br3IVA>. Acesso em: 9 mar. 2015.

HJALAGER, A. M. Repairing innovation defectiveness in tourism. Tourism management, v. 23, n. 5 , p. $465-474,2002$.

HOLLOWAY, J. C. The guided tour a sociological approach. Annals of Tourism Research, v. 8, n. 3, p. 377-402, 1981.

HORN, D.; SALVENDY, G. Consumer-based assessment of product creativity: a review and reappraisal. Human factors and ergonomics in manufacturing \& service industries, v. 16, p. 155-175, 2006.

HSIAO, S. W.; CHOU, J. R. A creativity-based design process for innovative product design. International Journal of Industrial Ergonomics, v. 34, n. 421-443, 2004.

JENSEN, R. The dream society: how the coming shift from information to imagination will transform your business. New York: McGraw-Hill, 1999.

MACHADO, L. P; ALMEIDA, A. Turismo: inovação e novas tecnologias. Porto: Sociedade Portuguesa de Inovação, 2010.

MATOS, F. C. Turismo receptivo e terceiro setor: ações de fomento. In: SEMINÁRIO DE PESQUISA EM TURISMO DO MERCOSUL, 7., 2012, Caxias do Sul. Anais ... Caxias do Sul: Universidade de Caxias do Sul, 2012.

MIDDLETON, V.T. C.; CLARKE, J. Marketing de turismo: teoria \& prática. Rio de Janeiro: Campus, 2002.

MORRISON, A. M. Marketing de hospitalidade e turismo. 4.ed. São Paulo: Cengage Learning, 2012. 
Tourism in Analysis

OLIVEIRA, M. P.; RECHIA, S. O espaço cidade: uma opção de lazer em Curitiba (PR). Licere, v. 12, p. 1-25, 2009.

PAZINI, R.; MANOSSO, F.C.; BIZINELLI, C.; GÂNDARA, J. M. G. G. Turismo receptivo: uma análise dos city tours de Curitiba. Turismo, Visão e Ação, Balneário Camboriú, v. 16, n. 3, p. 599-628,2014.

PELIZZER, H. A. Gestão do turismo receptivo e hospitalidade. In: SEMINÁRIO DAASSOCIAÇÃO BRASILEIRA DE PESQUISA E PÓS-GRADUAÇÃO EM TURISMO, 4., 2007, São Paulo. Anais... São Paulo: ANPTUR, 2007.

PINE II, J.; GILMORE, J. H. The experience economy: work is theater \& every business a stage. Brighton: Harvard Business School Press, 1999.

PULIDO-FERNÁNDEZ, J. I.; NAVARRO HERMOSO, U. Identificación de ítems para medir las experiencias del turista en destino. Cultur, v. 8, n. 1, p. 4-34, 2014.

RICHARDS, G.; WILSON, J. Developing creativity in tourist experiences: a solution to the serial reproduction of culture? Tourism Management, v. 27, p. 1408-1413, 2006.

RUIZ, T. C. D.; GÂNDARA, J. M. G. A relação entre o planejamento urbano e a competitividade dos destinos turísticos. Revista Brasileira de Pesquisa em Turismo, Balneário Camboriú, v. 7, n. 2, p. $260-280,2013$.

SOARES, J. C. M. et al. Níveis e formas de inovação nos empreendimentos da cadeia produtiva do turismo em Tibau do Sul/RN. Revista de Turismo Contemporâneo, Natal, v. 1, n. 1, 2013.

TAVARES, A. de M. City tour. São Paulo: Aleph, 2002.

TELLES, D. H. Q.; GÂNDARA, J. M. G. Impactos socioculturais no processo de turistificação da Vila de Encantadas, Ilha do Mel, Paraná, Brasil. Turismo e Sociedade, Curitiba, v. 5, n. 1, p. 183-208, 2012.

TONON, L. M. P. A territorialização e o marketing de um produto turístico regional: o passeio de trem Curitiba/Litoral. 2014. 278 f. Dissertação (Mestrado em Geografia) - Universidade Federal do Paraná, Curitiba, 2014.

WEIERMAIR, K. Product improvement or innovation: what is the key to success in tourism. 2004. Disponível em: <http://bit.ly/2g71mZz>. Acesso em: 27 nov. 2016.

WONG, C. U. I.; MCKERCHER, B. Day tour itineraries: searching for the balance between commercial needs and experiential desires. Tourism Management, v. 33, n. 6, p. 1360-1372, 2012.

Recebido em: 13/10/2015 (1 ${ }^{\mathrm{a}}$ versão) 10/09/2016 ( $2^{\mathrm{a}}$ versão) $05 / 10 / 2016$ (3 ${ }^{\mathrm{a}}$ versão)

Aprovado em: 15/10/2016 